\title{
Vitamin D deficiency among patients with pulmonary hypertension
}

Andrés N. Atamañuk ${ }^{1,2^{*}}$, Diego F. Litewka' ${ }^{1}$ Sergio J. Baratta², Ignacio M. Seropian³, Graciela Perez Prados ${ }^{1}$, Miguel O. Payaslian ${ }^{1}$, Juan P. Ortiz Fragola ${ }^{1}$ and Pilar Escribano Subias ${ }^{4}$

\begin{abstract}
Background: There is little information about vitamin D (Vit D) deficiency in patients with pulmonary hypertension $(\mathrm{PH})$. The objective of this study was: 1) compare Vit D levels between patients with $\mathrm{PH}$, left ventricular failure (LVF) and healthy subjects (HS); 2) correlate, in patients with PH, Vit D levels with prognosis-related variables, such as the 6-min walk test (6MWT).

Methods: Vitamin D levels were measured in a cross-sectional study in 126 patients from one of three groups: patients with $\mathrm{PH}(n=53)$, patients with LVF $(n=42)$ and healthy subjects $(n=31)$. In all groups, 8- $h$ fasting blood samples were obtained in the morning. In the PH and the LVF group, functional class (WHO criteria), metres covered in the 6MWT and echocardiographic parameters were analysed. In the PH group, plasma N terminal pro B type natriuretic peptide (NT-proBNP) level was analysed and a complete haemodynamic evaluation by right heart catheterisation was made.

Results: Mean Vit D levels were lower in PH than in both other groups ( $\mathrm{ng} / \mathrm{ml}$, mean $\pm \mathrm{SD}$ ): PH $19.25 \pm 10$, LVF $25.68 \pm 12$, HS $28.8 \pm 12$ (PH vs LVF $p=0.017$, PH vs HS $p=0.001$ and HS vs LVF $p=0.46$ ). Vit D deficiency prevalence was higher in PH as compared to the other groups (PH 53.8\%, LVF 45.2\%, HS 25\%, $p=0.01$ ). Patients with PH in functional class (FC; WHO criteria) III-IV had higher Vit D deficiency prevalence than those in FC I-II $(86.7 \%$ vs $40.5 \%, p=0.003)$. There was a significant linear correlation between the $6 \mathrm{MWT}$ and Vit D levels in PH $(p<0.01)$, but not in LVF $(p=0.69)$.
\end{abstract}

Conclusions: Vit D levels were lower in patients with PH as compared to patients with LVF and HS and correlated directly with 6-min walk distance.

Keywords: Pulmonary hypertension, Pulmonary arterial hypertension, Vitamin D, Vitamin deficiency

\section{Background}

Vitamin D (Vit D), typically associated with phosphocalcium metabolism and bone disease, has been shown to influence several pathways that affect myocardial function and/or structure. As early as 1981, a reduction in cardiovascular mortality during the summer season was observed and it was attributed to higher Vit D levels produced by increased sun exposure [1].

Vit D receptors are present in several tissues associated with the cardiovascular system, such as cardiomyocytes,

\footnotetext{
* Correspondence: aatamanu@cas.austral.edu.ar

'División Cardiología y Servicio de Neumonología, Hospital General de

Agudos "Juan A. Fernández", Ciudad Autónoma de Buenos Aires, Argentina

${ }^{2}$ Instituto de Cardiología y Terapéutica Cardiovascular, Hospital Universitario

Austral, Buenos Aires, Argentina

Full list of author information is available at the end of the article
}

vascular smooth muscle and endothelial cells [1-3]. Vit D can suppress both the renin-angiotensin system (RAS) and inflammation $[4,5]$. Vit D deficiency, and consequent elevated plasma renin activity, can induce ventricular remodelling and increase arterial blood pressure [6, 7]. In addition, Vit $\mathrm{D}$ locally reduces the expression of genes that increase myocardial hypertrophy [8]. Vit D may also prevent ventricular hypertrophy by increasing thrombomodulin and it has multiple effects on cardiomyocyte development and differentiation $[9,10]$.

Pulmonary hypertension $(\mathrm{PH})$ is a low-prevalence, lifethreatening disorder. Understanding $\mathrm{PH}$ physiopathology is essential to establish prognostic factors and to propose newer therapies. Vit D deficiency is more prevalent in patients with left ventricular failure (LVF) than in 
healthy subjects (HS) and it is strongly related to heart failure evolution [9]. The objective of this study is to compare Vit D levels in three groups: 1) patients with $\mathrm{PH}$; 2) patients with LVF; and 3) a control population of HS. Also within the PH group we intended to correlate Vit $\mathrm{D}$ deficit with clinical variables with prognostic value such as the 6-min walk test (6MWT).

\section{Methods}

\section{Study population}

This cross-sectional study included three groups of patients: A) Patients with $\mathrm{PH}$ (consecutively recruited from the Pulmonary Hypertension program, Juan A. Fernández General Hospital, Buenos Aires, Argentina, followed from February 2011 to February 2016). The PH diagnosis was defined by heart catheterisation: presence of mean pulmonary arterial pressure (MPAP) $\geq 25 \mathrm{mmHg}$ and pulmonary artery wedge pressure (PAWP) $\leq 15$ $\mathrm{mmHg}$; B) Patients with LVF (recruited from the Heart Failure program, Juan A. Fernández General Hospital, Buenos Aires, Argentina, from December 2011 to February 2016) defined by echocardiographic evidence of left ventricular ejection fraction (LVEF) $<35 \%$ and no right ventricular compromise; C) Healthy subjects (recruited among patients' relatives and hospital workers, from December 2011 to March 2016): no known medical conditions or chronic medications and normal physical exam, electrocardiogram and cardiac ultrasonography.

Table 1 Basal characteristics of patients with $\mathrm{PH}$ divided by $\mathrm{PH}$ sub-group

\begin{tabular}{|c|c|c|c|c|c|c|c|c|}
\hline PH subgroups & Total $(n=53)$ & Idiopathic $(n=16)$ & CTD $(n=9)$ & Congenital $(n=16)$ & $\mathrm{HIV}(n=6)$ & Toxic $(n=1)$ & CTEPH $(n=5)$ & $p$ value \\
\hline Age (years; $x \pm S D$ ) & $40.8 \pm 16.5$ & $38.5 \pm 19.1$ & $53 \pm 14.9$ & $33.2 \pm 15.5$ & $42.7 \pm 6.4$ & 47 & $45.4 \pm 11.7$ & 0.10 \\
\hline Females (\%) & 73.6 & 81.25 & 100 & 75 & 66.6 & 0 & 40 & 0.04 \\
\hline \multirow[t]{2}{*}{ FC (\%) } & 71.2 & 62.5 & 44.4 & 100 & 33.3 & 100 & 100 & 0.01 \\
\hline & 28.8 & 37.5 & 66.6 & 0 & 66.7 & 0 & 0 & 0.01 \\
\hline $\mathrm{Ht}(\% ; \mathrm{x} \pm \mathrm{SD})$ & $43.9 \pm 8.9$ & $42.8 \pm 5.7$ & $40.3 \pm 5.3$ & $50.7 \pm 11.4 *$ & $38.8 \pm 9.1$ & 42.1 & $42.1 \pm 7.9$ & 0.03 \\
\hline Urea (mg/ml; x $x \pm S D)$ & $34.49 \pm 12.1$ & $32.63 \pm 9.6$ & $32.50 \pm 12.1$ & $36.92 \pm 17.1$ & $33.33 \pm 11.6$ & 34 & $38 \pm 5.2$ & 0.91 \\
\hline Creatinine (mg/dl; $x \pm S D)$ & $0.96 \pm 0.9$ & $0.76 \pm 0.1$ & $0.9 \pm 0.1$ & $1.29 \pm 1.7$ & $0.71 \pm 0.1$ & 1.4 & $0.98 \pm 0.1$ & 0.69 \\
\hline Sodium (mEq/Lt; $x \pm S D)$ & $140.4 \pm 2.6$ & $139.7 \pm 2.2$ & $142.7 \pm 2.2$ & $140.4 \pm 2.3$ & $140.2 \pm 2.8$ & 141 & $138.8 \pm 3.2$ & 0.13 \\
\hline Bilirubine (mg/dl; $x \pm S D$ ) & $1.14 \pm 1$ & $1.14 \pm 0.9$ & $0.72 \pm 0.1$ & $1 \pm 0.3$ & $1.21 \pm 1.3$ & 1 & $2.08 \pm 2.2$ & 0.35 \\
\hline \multicolumn{9}{|l|}{6 -min walk test $(x \pm S D)$} \\
\hline Distance (m) & $392.5 \pm 132.2$ & $395.8 \pm 114$ & $337.2 \pm 136.7$ & $440.5 \pm 114.5$ & $294.1 \pm 160.7$ & 557 & $430 \pm 146.2$ & 0.11 \\
\hline Saturated $\mathrm{O}_{2}$, basal (\%) & $94.5 \pm 5.3$ & $96.7 \pm 3.3$ & $95.1 \pm 1.2$ & $90.8 \pm 7.9 *$ & $96.3 \pm 1.3$ & 98 & $95.25 \pm 2.8$ & 0.04 \\
\hline Desaturation & $-6.20 \pm 6$ & $-5.33 \pm 5.52$ & $-8.33 \pm 3.93$ & $-9.07 \pm 7.2$ & $-2.67 \pm 4.76$ & -1 & $-2.75 \pm 4.99$ & 0.14 \\
\hline Borg basal & $0.42 \pm 0.86$ & $0.57 \pm 1.01$ & $0.86 \pm 1.18$ & $0.17 \pm 0.57$ & $0.42 \pm 0.80$ & 0 & 0 & 0.50 \\
\hline Borg final & $3.35 \pm 2.36$ & $3.57 \pm 2.34$ & $3.93 \pm 3.14$ & $2.50 \pm 2.06$ & $4 \pm 2.36$ & 3 & $3 \pm 2.58$ & 0.79 \\
\hline \multicolumn{9}{|l|}{ Haemodynamic variables $(x \pm S D)$} \\
\hline $\mathrm{SBP}(\mathrm{mmHg})$ & $116.18 \pm 17.76$ & $110 \pm 16.16$ & $126.44 \pm 18.37$ & $114.45 \pm 19.6$ & $113.33 \pm 17.51$ & 135 & $117.5 \pm 12.58$ & 0.31 \\
\hline $\mathrm{DBP}(\mathrm{mmHg})$ & $71.25 \pm 10.59$ & $71.23 \pm 10.10$ & $73.22 \pm 15.03$ & $67.73 \pm 8.17$ & $70 \pm 8.94$ & 85 & $75 \pm 10$ & 0.60 \\
\hline $\mathrm{HR}$ (bts/min) & $81.9 \pm 13$ & $80.8 \pm 15.1$ & $83.4 \pm 14.3$ & $80 \pm 11.4$ & $88.2 \pm 12.6$ & 79 & $80.3 \pm 13.5$ & 0.89 \\
\hline MPAP $(\mathrm{mmHg})$ & $50.6 \pm 17.7$ & $55.7 \pm 16.6$ & $45.3 \pm 6$ & $56.7 \pm 28.6$ & $51.4 \pm 7.7$ & 29 & $38.8 \pm 10.8$ & 0.24 \\
\hline PAWP (mmHg) & $10.9 \pm 3.2$ & $11 \pm 2.7$ & $9.8 \pm 3.4$ & $11.8 \pm 4.7$ & $12.2 \pm 2.3$ & 8 & $10 \pm 2.5$ & 0.63 \\
\hline $\mathrm{RAP}(\mathrm{mmHg})$ & $8.6 \pm 4.2$ & $8.6 \pm 4.5$ & $8.1 \pm 3.5$ & $9.3 \pm 3.2$ & $10 \pm 5.1$ & 2 & $8.4 \pm 5.7$ & 0.66 \\
\hline PVR (Wood units) & $8.71 \pm 4.04$ & $9.27 \pm 2.34$ & $8.88 \pm 3.07$ & $8.43 \pm 7.05$ & $10.44 \pm 4.40$ & 3.9 & $6.57 \pm 3.48$ & 0.56 \\
\hline $\mathrm{Cl}\left(\mathrm{bts} / \mathrm{min} / \mathrm{m}^{2}\right)$ & $2.73 \pm 0.91$ & $2.7 \pm 0.69$ & $2.12 \pm 0.34$ & $3.38 \pm 1.33$ & $2.4 \pm 0.33$ & 3.8 & $2.9 \pm 1.13$ & 0.07 \\
\hline \multicolumn{9}{|l|}{ Treatment } \\
\hline Oral anticoagulation (n) & 24 & 8 & 6 & 3 & 2 & 1 & 4 & - \\
\hline Calcium channel blockers ( $n$ ) & 11 & 4 & 3 & 2 & 1 & 0 & 1 & - \\
\hline PDE5 inhibitors $(n)$ & 34 & 11 & 6 & 10 & 4 & 0 & 3 & - \\
\hline Endothelin antagonists ( $n$ ) & 11 & 4 & 1 & 5 & 1 & 0 & 0 & - \\
\hline Prostanoids (n) & 3 & 3 & 0 & 0 & 0 & 0 & 0 & - \\
\hline
\end{tabular}

${ }^{*} p<0.05$ vs rest of sub-groups. BTS beats; Cl cardiac Index; CTD connective tissue disorder; CTEPH chronic thromboembolic pulmonary hypertension; $D B P$ diastolic blood pressure; FC functional class; $H t$ hematocrit; $H R$ heart rate; MPAP mean pulmonary artery pressure; $P A W P$ pulmonary artery wedge pressure; PDE phosphodiesterase; PVR pulmonary vascular resistance; RAP right atrial pressure; SBP systolic blood pressure; Vit $D$ vitamin D 
In the $\mathrm{PH}$ and the LVF groups, functional class (FC; WHO criteria), metres covered in the 6MWT and echocardiographic parameters (e.g., value of pulmonary artery systolic pressure, PASP, by the analysis of tricuspid regurgitation velocity; right ventricular systolic function, measured by tricuspid annular plane systolic excursion, [right ventricular dysfunction defined as TAPSE $<20 \mathrm{~mm}$ ]; LVEF; among others) were analysed. In the $\mathrm{PH}$ group, plasma $\mathrm{N}$ terminal pro B type natriuretic peptide (NT-proBNP) level was analysed and a complete haemodynamic evaluation by right heart catheterisation was made.

In all groups, 8-h fasting blood samples were obtained in the morning. Serum Vit D levels were determined measuring 25-hydroxy Vit D using the electrochemoluminescence method (Cobas, Roche). Vit D deficiency was defined as a level of Vit $\mathrm{D}<20 \mathrm{ng} / \mathrm{ml}$. Patients being treated with Vit $\mathrm{D}$, calcium supplements or receiving treatment for osteoporosis, patients with hyperparathyroidism or on dialysis and those who had been hospitalised for any reason in the previous 3 months, were excluded.

\section{Statistical analysis}

Discrete variables were expressed as frequencies and percentages. Continuous variables were analysed with ANOVA and expressed as the mean with standard deviation. Association between qualitative variables was evaluated using the chi-square test with the Yates correction or the Fisher's exact test. The correlation between continuous variables was analysed with the Spearman's correlation coefficient. A $p$ value $<0.05$ was considered significant in all cases. Due to the exploratory nature of the study, $p$-values were not corrected for multiple testing.

\section{Results}

Fifty three patients diagnosed with $\mathrm{PH}, 42$ patients with LVF and $31 \mathrm{HS}$ were included. General characteristics of patients with $\mathrm{PH}$ are shown in Table 1. A significantly higher haematocrit and lower basal haemoglobin saturation was found in the congenital PH group. Characteristics of the left ventricular failure and healthy subjects groups are shown in Table 2. Within the $\mathrm{PH}$ group, 48 patients corresponded to international classification Group 1 $\mathrm{PH}$ (16 idiopathic, 16 congenital, 9 associated with connective tissue diseases [CTD], $6 \mathrm{HIV}$ and 1 drug/toxin-induced) and 5 to Group 4 (chronic thrombo-embolic pulmonary hypertension) [11]; only 36 patients (68\%) of the whole $\mathrm{PH}$ group received specific treatment. Time from the onset of symptoms to diagnosis (right heart catheterization) was $41.1 \pm 47$ months, mean time from diagnosis to Vit D measurement was $86.3 \pm 33$ days; mean NT-proBNP at diagnosis was $610.2 \pm 780 \mathrm{pg} / \mathrm{ml}$. Sample distribution according to $\mathrm{FC}$ was: I $46.2 \%$, II $25 \%$, III
Table $\mathbf{2}$ Characteristics of the left ventricular failure and healthy subjects groups

\begin{tabular}{|c|c|c|c|c|}
\hline \multicolumn{2}{|c|}{ 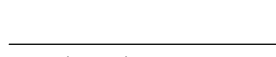 } & $\mathrm{PH}(n=53)$ & $\operatorname{LVF}(n=42)$ & $\mathrm{HS}(n=31)$ \\
\hline \multicolumn{2}{|c|}{ Age (years) } & $40.8 \pm 16.5$ & $58.6 \pm 10 *$ & $40.5 \pm 17$ \\
\hline \multicolumn{2}{|c|}{ Females (\%) } & 73.6 & $28.9 *$ & 74.2 \\
\hline \multicolumn{2}{|c|}{$\mathrm{BMI}\left(\mathrm{kg} / \mathrm{m}^{2}\right)$} & $26.2 \pm 5$ & $30.9 \pm 6 *$ & $25.2 \pm 4$ \\
\hline \multirow[t]{2}{*}{ FC (\%) } & $|-| \mid$ & 71.2 & 86.7 & - \\
\hline & III-IV & 28.8 & 13.3 & - \\
\hline \multicolumn{2}{|c|}{ VitD (mg/dL) } & $19.25 \pm 10.1 *$ & $25.68 \pm 12$ & $28.8 \pm 12$ \\
\hline \multicolumn{2}{|l|}{$\mathrm{Ht}(\%)$} & $43.9 \pm 8.9$ & $40.9 \pm 7.5$ & $40.6 \pm 5.3$ \\
\hline \multicolumn{2}{|c|}{ Urea $(\mathrm{mg} / \mathrm{mL})$} & $34.49 \pm 12.1$ & $45.63 \pm 16.3$ & $33.6 \pm 9.2 * *$ \\
\hline \multicolumn{2}{|c|}{ Creatinine (mg/\%) } & $0.96 \pm 0.9$ & $1.04 \pm 0.6$ & $0.75 \pm 0.3$ \\
\hline \multicolumn{2}{|c|}{ Sodium (mEq/Lt) } & $140.4 \pm 2.6$ & $137.7 \pm 6.2$ & $140 \pm 2.9$ \\
\hline \multicolumn{2}{|c|}{ Total bilirubin (mg/dL) } & $1.14 \pm 1$ & $0.76 \pm 0.8$ & $0.57 \pm 0.2 \#$ \\
\hline \multicolumn{2}{|c|}{ LVEF (\%) } & $61.9 \pm 7$ & $34.3 \pm 10 *$ & $65.4 \pm 8$ \\
\hline \multicolumn{2}{|c|}{ LVDD (mm) } & $43.5 \pm 6$ & $65.6 \pm 10 *$ & $48.3 \pm 23$ \\
\hline \multicolumn{2}{|c|}{ LA (mm) } & $35.6 \pm 8$ & $46.84 \pm 15 *$ & $39.7 \pm 7$ \\
\hline \multicolumn{2}{|c|}{ SPAP $(\mathrm{mmHg})$} & $81.55 \pm 3 *$ & $43.91 \pm 23$ & $31.84 \pm 15^{* *}$ \\
\hline
\end{tabular}

23.1\% and IV 5.8\%. Right heart catheterisation showed (mean \pm SD): MPAP $50.6 \pm 17 \mathrm{mmHg}$, right atrial pressure $8.6 \pm 4 \mathrm{mmHg}$, PAWP $10.9 \pm 3 \mathrm{mmHg}$, cardiac index $2.7 \pm 1 \mathrm{l} / \mathrm{min} / \mathrm{m}^{2}$, pulmonary vascular resistance $8.7 \pm 4$ Wood units (WU) and heart rate $81.9 \pm 13 / \mathrm{min}$. In the LVF group, mean LVEF was $34.3 \pm 10 \%$ and mean left ventricular diastolic diameter was $65.6 \pm 10 \mathrm{~mm}$. In this group, $86.7 \%$ of patients were in FC I-II. Patients with $\mathrm{PH}$ showed a non-significant trend to higher and more advanced FC (FC III-IV in PH vs LVF; 28.8 vs $13.3 \%$, $p=0.064)$.

Mean Vit D level was significantly lower in the $\mathrm{PH}$ group $(19.25 \pm 10 \mathrm{ng} / \mathrm{ml})$ compared with the LVF group $(25.68 \pm 12 \mathrm{ng} / \mathrm{ml}, p=0.017$; Fig. 1$)$ and HS $(28.8 \pm 12 \mathrm{ng} / \mathrm{ml} p=0.001)$. There were no significant differences in Vit D levels between LVF and HS (HS vs LVF $p=0.46$; Fig. 1) or among the different $\mathrm{PH}$ sub-groups (Table 1). The prevalence of Vit D deficiency was significantly higher in $\mathrm{PH}$ compared with LVF and HS (PH: $53.8 \%$ vs LVF: $45.2 \%$ and HS: $25 \%$, $p<0.01$; Fig. 2).

In the PH group, patients in FC III-IV showed greater prevalence of Vit $\mathrm{D}$ deficiency compared with patients in FC I-II $(86.7 \%$ vs $40.5 \%, p=0.003)$. In this same group, our study found a tendency to a greater prevalence of Vit $\mathrm{D}$ deficiency in patients with right ventricular dysfunction $(p=0.052)$. In addition, a higher prevalence of Vit D deficit was found in patients with high PASP measured by echocardiography $(p=0.038)$. A significant linear correlation $(\mathrm{r}=0.36 ; p=0.01)$ was found between metres covered in the $6 \mathrm{MWT}$ and Vit D levels in the PH 


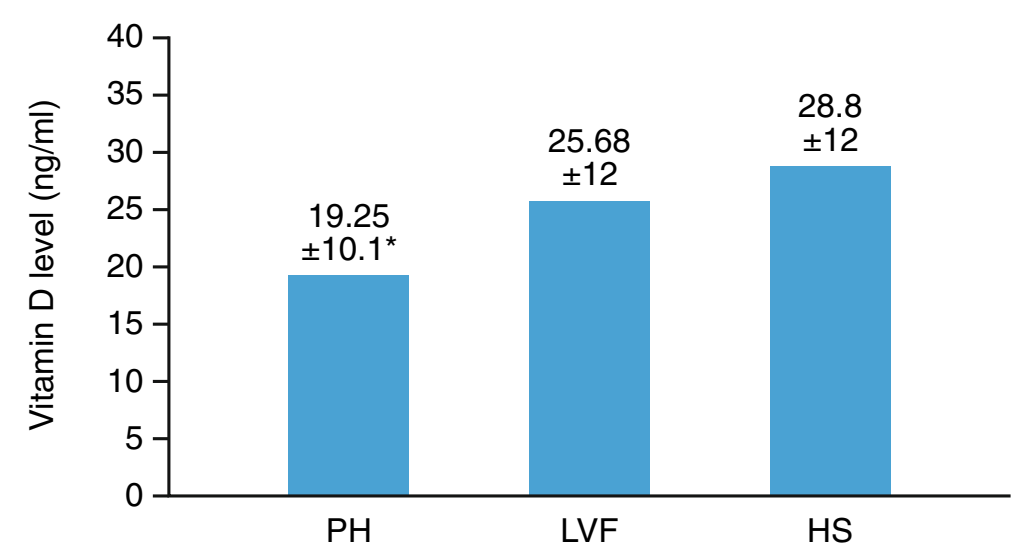

Fig. 1 Vit D levels in the different study groups, expressed as $\mathrm{ng} / \mathrm{ml}$. *Significant differences were found between PH and LVF groups $(p=0.017)$ and between PH group and HS ( $p=0.001)$. Difference between LVF and HS groups was not significant $(p=0.046)$. HS, healthy subjects; LVF, left ventricular failure; $\mathrm{PH}$, pulmonary hypertension; Vit D, vitamin D

group, but not in the LVF ( $p=0.69$; Fig. 3). No significant differences were found between $\mathrm{PH}$ group and LVF group in the distance covered in 6MWT $(392.5 \pm 132 \mathrm{~m}$, $\mathrm{PH}$ vs $409.1 \pm 99 \mathrm{~m}$, LVF, $p=0.5)$.

\section{Discussion}

Pulmonary hypertension is a disabling and potentially fatal disorder characterised by a progressive increase in pulmonary vascular resistance leading to right ventricular impairment and heart failure [11]. Main treatments act on known physiopathological pathways: endothelin, nitric oxide, prostacyclin and the coagulation system. Patients may also be affected by other complications, such as Vit D deficiency [12, 13].

Vit D appears to be related to arterial blood pressure control through different pathways and is inversely correlated with serum renin activity [14]. Evidence suggests a link between Vit D and cardiovascular disease, including experimental studies that identify Vit
D receptors in vascular smooth muscle cells, endothelial cells and in cardiac muscle tissue [15]. Although not clearly related, some previous studies suggest a higher prevalence of Vit D deficiency in patients with PH [13, 16-18].

Our study shows that mean Vit D levels are significantly lower in patients with $\mathrm{PH}$ compared with both HS and patients with LVF. In addition, prevalence of Vit D deficiency is significantly higher in patients with $\mathrm{PH}$ compared to HS and to patients with LVF. Vit D deficiency in the $\mathrm{PH}$ group was associated with poorer $\mathrm{FC}$ and worse echocardiographic parameters. No correlation between Vit D levels and haemodynamic parameters measured by right heart catheterisation was found; this may be because diagnostic catheterisation differed temporarily with Vit D dosage. Significant correlation between exercise capacity measured with the 6-min walk distance test and Vit D levels was observed, establishing that the lower the Vit D levels, the shorter

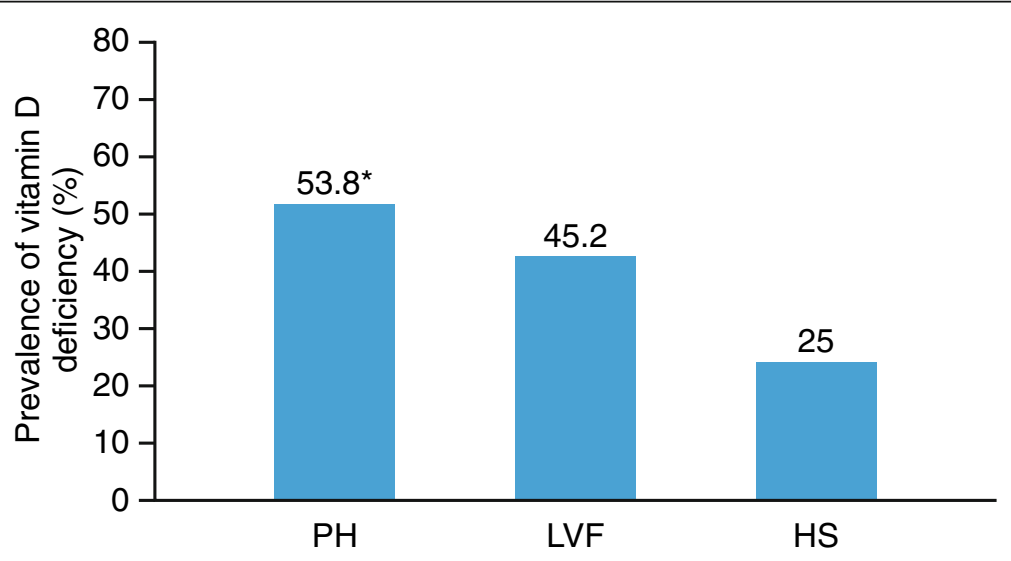

Fig. 2 Prevalence of Vit D deficiency in the different study groups, expressed as percentages. * Differences were significant, $p<0.01, \mathrm{PH}$ versus LVF and HS. HS, healthy subjects; LVF, left ventricular failure; PH, pulmonary hypertension; Vit D, vitamin D 


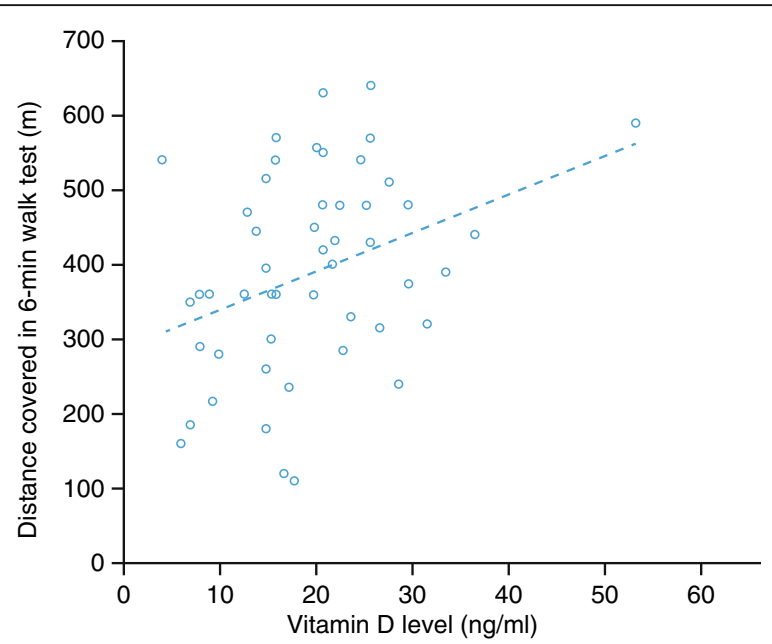

Fig. 3 The $6 \mathrm{MWT}$ in the $\mathrm{PH}$ group. Significant correlation between distance covered in 6MWT (metres) and Vit D level (ng/ml), p $<0.01$ (bilateral). Spearman's rho correlation coefficient 0.36. 6MWT, 6-min walk test; PH, pulmonary hypertension; Vit D, vitamin D

the distance covered. The 6MWT is a well-known prognostic factor in patients with $\mathrm{PH}$.

Interestingly, a significant difference between Vit D levels in PH and LVF groups was found. Although an activation of the RAS and the sympathetic nervous system may be found in both LVF and PH, no studies have described differences in the magnitude of these phenomena between both disorders [20]. Vit D deficiency and its relationship with these pathways might be different in both diseases. Although Vit D receptors in myocardial cells and cardiac fibroblasts exist, it remains unknown if their function or concentrations are different between left and right ventricle [21, 22].

With some exceptions, the characteristics of the $\mathrm{PH}$ patient cohort were similar to those found in international registries [23]. They differed in age and FC at the time of diagnosis: both came out to be somewhat lower in our study than in most available data. Vit D levels and demographic characteristics in our LVF population are similar to those found in other studies [2425]. Vit D deficiency is more frequently observed in elderly patients. Despite being younger than patients in the LVF group, patients with PH had lower Vit D levels [26]. Only $68 \%$ of patients included in our study received PAH-specific treatment; unfortunately, due to bureaucratic considerations in our country, there is a considerable delay between the PAH diagnosis and the actual access to specific treatment drugs.

As with other chronic cardiovascular conditions, we do not know if Vit D deficit is a cause or a consequence of $\mathrm{PH}$. There is an established relationship between inflammatory factors and Vit D, with Vit D being protective in inflammatory conditions [27-29].
Some limitations of our study should be addressed. Catheterization and hemodynamic analysis differed temporarily with Vit D dosage, a fact that could represent a potential source of bias. Also, the reduced sample size and did not allow us to correlate specific PAH treatment with Vit D levels or to adequately compare Vit D levels between different PH subgroups.

\section{Conclusions}

At present, there is limited scientific evidence of the relationship between $\mathrm{PH}$ and Vit D deficiency. This study shows that patients with $\mathrm{PH}$ have lower Vit D levels and a higher prevalence of Vit D deficiency compared to HS and to patients with LVF. In addition, a relationship between Vit D deficiency in patients with $\mathrm{PH}$ and poor prognosis-associated variables was found. It will be interesting to establish whether patients with $\mathrm{PH}$ and Vit $\mathrm{D}$ deficiency should be treated with Vit D supplements to improve disease prognosis.

\section{Abbreviations \\ 6MWT: 6-min walk test; CTD: Connective tissue diseases; FC: Functional class; HS: Healthy subjects; LVEF: Left ventricular ejection fraction; LVF: Left ventricular failure; MPAP: Mean pulmonary arterial pressure; \\ PAWP: Pulmonary artery wedge pressure; PH: Pulmonary hypertension; RAS: Renin--angiotensin system; TAPSE: Tricuspid annular plane systolic excursion; Vit D: Vitamin D}

\section{Acknowledgements}

Assistance in finalising the manuscript for submission was provided by Richard McDonald of Watermeadow Medical, funded by Actelion Pharmaceuticals Ltd.

\section{Authors' contributions}

ANA and DFL conceived and designed the experiment, and wrote the manuscript; SJB analysed the data; IMS, GPP and MOP performed the experiment; JPOF analysed the data, and wrote the manuscript; PES designed the experiment, and wrote the manuscript. All authors have approved the manuscript.

\section{Funding}

English language editorial assistance in finalising the manuscript for submission was provided by Richard McDonald of Watermeadow Medical, funded by Actelion Pharmaceuticals Ltd. Actelion Pharmaceuticals Ltd. did not have any role in the design of the study or in the collection, analysis, or interpretation of the published data.

\section{Availability of data and materials}

The datasets used and/or analysed during the current study were complete (no missing values) and are available from the corresponding author on reasonable request.

\section{Ethics approval and consent to participate}

The committee that approved this study was Comite de ética en investigación del Hospital General de Agudos Juan A. Fernández (Research Ethic Committee, Juan A. Fernández General Hospital) (reference number: CEIHF201930). Verbal informed consent was obtained and registered in the clinical record. Consent was obtained verbally because there was no intervention and the study represented no potential harm or danger to the patients. The IRB approved the verbal method of obtaining consent.

Consent for publication

Not applicable. 


\section{Competing interests}

The authors declare no conflict of interest.

\section{Author details}

'División Cardiología y Servicio de Neumonología, Hospital General de Agudos "Juan A. Fernández", Ciudad Autónoma de Buenos Aires, Argentina. 2Instituto de Cardiología y Terapéutica Cardiovascular, Hospital Universitario Austral, Buenos Aires, Argentina. ${ }^{3}$ Servicio de Hemodinamia, Hospital Italiano de Buenos Aires, Buenos Aires, Argentina. ${ }^{4}$ Servicio de Cardiología, Hospital Universitario 12 de Octubre, Madrid, Spain.

Received: 28 November 2017 Accepted: 25 November 2019

Published online: 21 December 2019

\section{References}

1. Scragg R. Seasonality of cardiovascular disease mortality and the possible protective effect of ultra-violet radiation. Int J Epidemiol. 1981;10:337-41.

2. Walters MR, Wicker DC, Riggle PC. 1,25-dihydroxyvitamin D3 receptors identified in the rat heart. J Mol Cell Cardiol. 1986;18:67-72.

3. Somjen D, Weisman Y, Kohen F, Gayer B, Limor R, Sharon O, et al. 25hydroxyvitamin D3-1alpha-hydroxylase is expressed in human vascular smooth muscle cells and is upregulated by parathyroid hormone and estrogenic compounds. Circulation. 2005;111:1666-7.

4. Wong MS, Delansorne R, Man RY, Vanhoutte PM. Vitamin D derivatives acutely reduce endothelium-dependent contractions in the aorta of the spontaneously hypertensive rat. Am J Physiol Heart Circ Physiol. 2008;295: 289-96

5. Li YC, Kong J, Wei M, Chen ZF, Liu SQ, Cao LP. 1,25-dihydroxyvitamin D(3) is a negative endocrine regulator of the renin-angiotensin system. J Clin Invest. 2002:110:229-38.

6. Van Etten E, Mathieu C. Immunoregulation by 1,25-dihydroxyvitamin D3: basic concepts. J Steroid Biochem Mol Biol. 2005;97:93-101.

7. Resnick LM, Müller FB, Laragh JH. Calcium-regulating hormones in essential hypertension. Relation to plasma renin activity and sodium metabolism. Ann Intern Med. 1986;105:649-54

8. Kong J, Kim GH, Wei M, Sun T, Li G, Liu SQ, et al. Therapeutic effects of vitamin D analogs on cardiac hypertrophy in spontaneously hypertensive rats. Am J Pathol. 2010;177:622-31.

9. Lindqvist $\mathrm{PG}$, Epstein $\mathrm{E}$, Olsson $\mathrm{H}$. Does an active sun exposure habit lower the risk of venous trombotic events? A D-lightful hypothesis J Thrombosis Haemostasis. 2009;7:605-10.

10. Ameri $\mathrm{P}$, Ronco D, Casu M. High prevalence of vitamin D deficiency and its association with left ventricular dilation: an echocardiography study in elderly patients with chronic heart failure. Nutr Metab Cardiovasc Dis. 2010; 20:633-40.

11. Galiè N, Humbert M. 2015 ESC/ERS guidelines for the diagnosis and treatment of pulmonary hypertension. The joint task force for the diagnosis and treatment of pulmonary hypertension of the European Society of Cardiology (ESC) and the European Respiratory Society (ERS). Eur Respir J. 2015:46:1855-6.

12. Humbert $M$, Sitbon $O$, Simonneau G. Treatment of pulmonary arterial hypertension. N Engl J Med. 2004;351:1425-36

13. Demir M, Uyan U, Keceoclu S, Demir C. The relationship between vitamin D deficiency and pulmonary hypertension. Prague Med Rep. 2013;114:154-61.

14. Bogaard HJ, Al Husseini A, Farkas L. Severe pulmonary hypertension: the role of metabolic and endocrine disorders. Pulm Circ. 2012;2:148-54

15. Anderson JL, May HT, Horne BD. Relation of vitamin D deficiency to cardiovascular risk factors, disease status, and incident events in a general healthcare population. Am J Cardiol. 2010;106:963-8.

16. Thadhani R, Appelbaum E, Pritchett Y. Vitamin D therapy and cardiac structure and function in patients with chronic kidney disease: the PRIMO randomized controlled trial. JAMA. 2012;307:674-84.

17. Mirdamadi A, Moshkdar P. Benefits from the correction of vitamin D deficiency in patients with pulmonary hypertension. Caspian J Intern Med. 2016;7:253-9.

18. Rios Fernández R, Fernández Roldán C, Callejas R, Ortego CN. Vitamin D deficiency in a cohort of patients with systemic scleroderma from the south of Spain. J Rheumatol. 2010:37:1355.

19. De Man F, Ly Tu M, Handoko L. Dysregulated renin-angiotensinaldosterone system contributes to pulmonary arterial hypertension. Am J Respir Crit Care Med. 2012;186:780-9.
20. Agnieszka C, Doan V, SI V-R. Prognostic significance of sympathetic nervous system activation in pulmonary arterial hypertension. Am J Respir Crit Care Med. 2010;181:1269-75.

21. O'Connell T, Simpson R. Immunochemical identification of the 1,25dihydroxyvitamin $\mathrm{d} 3$ receptor protein in human heart. Cell Biol Int. 1996;20:621-4.

22. Chen S, Glenn D, Ni W. Expression of the vitamin D receptor is increased in the hypertrophic heart. Hypertension. 2008;52:1106-12.

23. McGoon M, Benza L, Escribano-Subias P. Pulmonary arterial hypertension. Epidemiology and registries. J Am Coll Cardiol. 2013;62:D51-9.

24. William T, Abraham KF, Adams GC. In-hospital mortality in patients with acute decompensated heart failure requiring intravenous vasoactive medications an analysis from the acute decompensated heart failure National Registry (ADHERE). J Am Coll Cardiol. 2005;46:57-64.

25. Thierer J, Belziti C, Francesia A. [Manejo ambulatorio de la insuficiencia cardíaca crónica en la Argentina: Estudio OFFICE IC]. Rev. Argent Cardiol. 2006;74:109-16.

26. Wei-Long J, Hai-Bo G, Zhang Y. Vitamin D supplementation in the treatment of chronic heart failure: a meta-analysis of randomized controlled trials. Clin Cardiol. 2016;39:56-61.

27. Alemzadeh R, Kichler J, Babar G, Calhoun M. Hypovitaminosis D in obese children and adolescents: relationship with adiposity, insulin sensitivity, ethnicity, and season. Metabolism. 2008;57:183-91.

28. Schleithoff SS, Zittermann A, Tenderich G, Berthold HK, Stehle P, Koerfer R. Vitamin D supplementation improves cytokine profile in patients with congestive heart failure: a double-blind, randomized, placebo-controlled trial. Am J Clin Nutr. 2006;83:754-9.

29. Muller K, Haahr PM, Diamant M, Rieneck K, Kharazmi A, Bendtzen K. 1,25dihydroxyvitamin D3 inhibits cytokine production by human blood monocytes at the post-transcriptional level. Cytokine. 1992;4:506-12.

\section{Publisher's Note}

Springer Nature remains neutral with regard to jurisdictional claims in published maps and institutional affiliations.

Ready to submit your research? Choose BMC and benefit from:

- fast, convenient online submission

- thorough peer review by experienced researchers in your field

- rapid publication on acceptance

- support for research data, including large and complex data types

- gold Open Access which fosters wider collaboration and increased citations

- maximum visibility for your research: over $100 \mathrm{M}$ website views per year

At $\mathrm{BMC}$, research is always in progress.

Learn more biomedcentral.com/submissions 